\title{
EDITORIAL
}

\section{La epidemia de tabaquismo y su control en Latinoamérica}

$\mathrm{E}^{1}$ tabaquismo es un serio problema de salud, ambiental y económico para los países y constituye un obstáculo para su desarrollo. Los productos del tabaco son los únicos, legalmente vendidos, que matan entre un tercio y la mitad de los consumidores crónicos cuando se usan tal cual lo sugiere el fabricante. ${ }^{1,2}$ Su uso no sólo enferma y mata a quienes lo consumen, sino también a quienes se exponen al humo del tabaco.

La principales razones del mantenimiento del consumo son su gran capacidad adictiva y la existencia de un poderoso vector, carente de ética, que obtiene enormes ganancias: la industria tabacalera.

Para enfrentar la epidemia de tabaquismo, que se estima podría matar a 1000 millones de personas en el siglo XXI, ${ }^{3}$ la Organización Mundial de la Salud impulsó el Convenio Marco para el control del Tabaco (CMCT-OMS), el cual fue aprobado en mayo de 2003 y entró en vigencia internacional el 27 de febrero de 2007, constituyéndose en el primer tratado internacional legalmente vinculante de salud pública. A la fecha, 169 países son Estados partes de dicho Convenio.

Se estima que en Latinoamérica y el Caribe la epidemia de tabaquismo sería responsable de 600000 muertes anuales. Las previsiones del CMCT-OMS sugieren que el tabaquismo seguirá aumentando y se triplicarían las muertes en los próximos años. ${ }^{4}$

A principios de siglo XXI, la situación era preocupante: alto nivel de consumo en los países del cono sur y creciente en el resto; el $94 \%$ de los ambientes cerrados estaban contaminados por humo de tabaco. ${ }^{5}$

A la situación epidemiológica se sumaban la falta de compromiso político para el control del tabaco, la ausencia de datos confiables y/o comparables sobre la magnitud, las características, las tendencias de consumo y el impacto sobre la salud y economía, el escaso compromiso de la sociedad civil (en especial de organizaciones de la salud), la muy escasa investigación nacional y regional, y fundamentalmente, una poderosa industria tabacalera que actuaba en forma organizada para socavar cualquier intento de implementación de políticas de control. Era difícil pensar, que en corto plazo, la situación pudiera cambiar en nuestra región.

Bajo el influjo del CMCT-OMS, que se transformó en un verdadero movimiento de salud pública mundial, además del liderazgo inicial de algunos países como Canadá y Brasil, del trabajo incansable de un puñado de activistas muy comprometidos, del apoyo y compromiso de organizaciones internacionales (American Cancer Society, International Development Research Centre, Campaign for Tobacco Free Kids, Framework Convention Aliance y otras) y regionales (como la Fundación Interamericana del Corazón) y la visión de la Organización Panamericana de la Salud para promover la iniciativa de ambientes libres de humo de tabaco, la situación del control del tabaco y las expectativas de progreso en la región han mejorado sustancialmente.

El avance registrado en estos últimos cinco años en la región ha sido, sencillamente, espectacular. Uruguay asumió una posición de liderazgo en 2005, seguido luego por Panamá, y desde entonces se ha iniciado entre los países una "saludable competencia" por implementar las políticas más efectivas en control del tabaco.

Hoy varios países de la región comenzaron a implementar sus principales estrategias y hay países que las han implementado o están en vías de implementarlas:

- Prohibición de fumar en los lugares cerrados de trabajo y del sector restaurantero: Uruguay, Panamá, Colombia, Guatemala, Perú, Paraguay y Honduras. Pero también otros países han avanzado en los ámbitos estatal/provincial/local, como la Ciudad de México (México) y varias provincias / estados de Argentina y Brasil.

- Amplias prohibiciones de la publicidad del tabaco (Panamá, Brasil, Chile, Uruguay, Colombia). 
- Advertencias sanitarias en los paquetes, que incluyen imágenes prominentes (Brasil, Chile, Venezuela, Uruguay, Panamá, Colombia, Guatemala, Perú, Paraguay y México). Es de destacar que Honduras se sumaría a Uruguay con advertencias en $80 \%$ de las cajetillas, siendo así los países más avanzados en el mundo en esta área.

- Aumento significativo de los impuestos, como en Panamá o Uruguay, país este último donde los impuestos llegaron a $72 \%$ del precio real de los cigarrillos. vidad:

Estas acciones comienzan a evidenciar su efecti-

- $\quad$ Disminución de prevalencia: Brasil (de 32 a 17.2\% en 10 años) y Uruguay (de 32 a $25 \%$ en cinco años).

- Aumento significativo de la recaudación fiscal (Uruguay).

- Disminución del ingreso por infarto agudo de miocardio: Uruguay (17.2\%).

La existencia de estos progresos no nos debe hacer creer que la batalla está ganada, ni debemos olvidarnos del poderoso enemigo que enfrentamos. La industria tabacalera está contraatacando y comienza a amenazar con litigios a los países de avanzada. Ante esta nueva fase, los países deberán responder a ella en forma cooperativa, y la OMS, la Secretaría de la Conferencia de las Partes (COP), así como la propia COP, deberían considerar estrategias para defender lo que se ha logrado hasta el momento.

En Latinoamérica hemos aceptado el reto. Está en nosotros lograr una Latinoamérica libre de tabaco, que sea un ejemplo en control del tabaco para el resto del mundo.

Dr. Eduardo Bianco* biancoeduardo1@gmail.com

Declaración de conflicto de intereses

Declaro no tener conflicto de intereses.

\section{Referencias}

I.World Health Organization. Why is tobacco a public health priority? Tobacco Free Initiative. Geneva:WHO [consultado: 2010 julio]. Disponible en: www.who.int/tobacco/health_priority/en/print.html.

2. Peto R, Lopez A, Boreham J, Thun M, Heath C. Mortality from Smoking in Developed Countries 1950-2000: Indirect estimates from national vital statistics. New York: Oxford University Press, 1994.

3.World Health Organization.WHO Report on the Global Tobacco Epidemic, 2008 - The MPOWER package [consultado: 2010 julio] Disponible en: www.who.int/tobacco/mpower/2008/en/index.html. 4. Building Public Awareness About Passive Smoking Hazards. Tobacco Control Strategy Planning, Companion Guide \#I.American Cancer Society, Inc, 2003.

5. Navas-Acien A, Peruga A, Breysse P, Zavaleta A, Blanco-Marquizo A, Pitarque R, et al. Secondhand Tobacco Smoke in Public Places in Latin America, 2002-2003. JAMA 2004; 29I(22):274I-2745.

\footnotetext{
* Director para Latinoamérica de Framework Convention Alliance Presidente del Centro de Investigación para la Epidemia de Tabaquismo (CIET Uruguay).
} 